\title{
Effect of matrine combined with cisplatin on the expression of XIAP in human rhabdomyosarcoma RD cells
}

\author{
$\mathrm{LI} \mathrm{LI}^{1-4}$, TIANYANG XUE ${ }^{5}$, WEI XU ${ }^{5}$ and BIN ZHOU ${ }^{1-4}$ \\ ${ }^{1}$ Department of Pediatrics, Xuzhou Central Hospital, Xuzhou; ${ }^{2}$ Department of Pediatrics, The Affiliated XuZhou Hospital \\ of Medical College of Southeast University; ${ }^{3}$ Department of Pediatrics, Xuzhou Clinical Medical College \\ of Nanjing University of Chinese Medicine, Jiangsu 221009; ${ }^{4}$ Department of Pediatrics, XuZhou Clinical School \\ of Xuzhou Medical College; ${ }^{5}$ Pediatric Hospital of The Affiliated Hospital of Xuzhou Medical College, \\ Xuzhou, Jiangsu 221000, P.R. China
}

Received March 5, 2016; Accepted September 16, 2016

DOI: $10.3892 / \mathrm{ol} .2016 .5150$

\begin{abstract}
The combined effects of matrine (Mat) and cisplatin on the survival and apoptosis of rhabdomyosarcoma (RMS) RD cells, as well as the possible mechanism of the synergistic effect of Mat and cisplatin were investigated in the present study. RMS RD cells were divided and treated as follows: control group, $5 \mathrm{mg} / \mathrm{l}$ cisplatin group, Mat groups $(0.5,1.0$ and $1.5 \mathrm{~g} / \mathrm{l})$, and Mat $(0.5,1.0$ and $1.5 \mathrm{~g} / \mathrm{l})$ combined with $5 \mathrm{mg} / \mathrm{l}$ cisplatin groups. An MTT assay and flow cytometry were applied to detect the survival and apoptotic rates, respectively, while RT-PCR was applied to detect the expression levels of $\mathrm{X}$-linked inhibitor of apoptosis protein (XIAP) mRNA in the RD cells of each group. The survival rates of RD cells in each experimental group were lower than in the control group, and the apoptotic rates were higher than those in the control group $(\mathrm{P}<0.05)$. An increase in drug concentrations led to the cell proliferation inhibitory and apoptotic rates of the single Mat groups increasing as a function of dose (pairwise comparison among the groups, $\mathrm{P}<0.05$ ), while the proliferation inhibitory and apoptotic rates of Mat combined with the cisplatin groups under different concentration were significantly higher than those of the single Mat and single cisplatin groups under the same concentration $(\mathrm{P}<0.01)$. The expression levels of XIAP mRNA in the RD cells of each experimental group were lower than those in the control group $(\mathrm{P}<0.05)$. Additionally, the expression levels of XIAP mRNA in the group treated with Mat and cisplatin were significantly lower than those of the single cisplatin and single Mat groups $(\mathrm{P}<0.01)$. In conclusion, Mat and cisplatin are capable of inhibiting the proliferation
\end{abstract}

Correspondence to: Dr Bin Zhou, Department of Pediatrics, Xuzhou Central Hospital, 199 Jiefang South Road, Xuzhou, Jiangsu 221009, P.R. China

E-mail: cnlkojh5408@163.com

Key words: human rhabdomyosarcoma RD cells, matrine, cisplatin, $\mathrm{X}$-linked apoptosis inhibition gene, chemotherapy, children of RD cells and inducing apoptosis by suppressing the XIAP mRNA expression levels.

\section{Introduction}

Matrine (Mat) is one of the main active ingredients of Chinese herbal medicine (1), such as Sophora alopecuroides, Sophora tonkinensis, and Radix Sophorae Flavescentis. Its pharmacological effects are quite extensive. Previous studies have focused on Mat in depth and its antitumor effect. It was previously identified that Mat is capable of inhibiting tumor cell proliferation and inducing apoptosis (1). It can also inhibit tumor angiogenesis, invasion, and metastasis as well as reverse tumor cell resistance to pharmacological agents. In addition, combined medication can enhance its efficacy (2). A large body of studies worldwide has reported that Mat treatment results in different degrees of inhibition on melanoma, lung, gastric, breast, ovarian and bladder cancers as well as others (3-9). However, studies on the effects of Mat on rhabdomyosarcoma (RMS), as well as those on the combined effects of Mat with other chemotherapeutic drugs on RMS are limited. The present study examined cisplatin, a chemotherapeutic drug commonly used to treat clinical cases of RMS, and whether its effectiveness can be improved when used in combination with Mat, to produce an antitumor effect.

$\mathrm{X}$-linked inhibitor of apoptosis protein (XIAP) is a new member of the IAP family and one of the most powerful inhibitors of apoptosis $(10,11)$. At present, XIAP has been shown to be a protein of universal expression. It is expressed in various human tissues $(12,13)$, but at low levels in normal cells and is increased in cancer cells (14-16). XIAP can inhibit tumor cell apoptosis and reduce tumor cell sensitivity, such as in ovarian cancer, glioma, prostate cancer, rectal cancer and childhood acute leukemia cells (17-20). However, to the best of our knowledge, there are few relevant studies reporting its role in children's RMS.

In the present study, XIAP was used as a reporter to examine the effect of Mat combined with cisplatin on human RMS cells, in order to identify a new option for the clinical treatment of RMS. 


\section{Materials and methods}

Reagents. The RMS RD cell line was purchased from the Chinese Academy of Sciences Cell Bank (Shanghai, China). Mat (purity $\geq 98 \%$ ) was purchased from Shaanxi Zhongxin Biotechnology Co., Ltd. (Shaanxi, China); the methyl hiazolyl tetrazolium (MTT) assay was purchased from Sigma (St.Louis, MO, USA); the flow cytometry kit (Annexin V-FITC kit) was purchased from Beijing Biosea Biotechnology Co., Ltd. (Beijing, China); and the total RNA extraction kit, and reverse transcription (RT)-PCR two-step kit were purchased from Tiangen Biotech (Beijing) Co., Ltd. (Beijing, China). The PCR primers were designed and produced by Sangon Biotech Co. Ltd. (Shanghai, China).

Cell culture. RD cells were grown in RPMI-1640 supplemented with $100 \mathrm{~g} / \mathrm{l}$ fetal bovine serum and $10 \mathrm{~g} / \mathrm{l}$ penicillin/streptomycin and maintained in a constant temperature incubator at $37^{\circ} \mathrm{C}$, and $50 \mathrm{ml} / 1 \mathrm{CO}_{2}$. The medium was changed once every 3-4 days, and cells were passaged once every 5-7 days. The cells were collected and used during the logarithmic phase of growth for all the experiments.

Experimental grouping and treatments. Grouping and treatments used were: i) Control group, only RMS RD cells, without any other processing; ii) $5 \mathrm{mg} / 1$ cisplatin group, $5 \mathrm{mg} / \mathrm{l}$ cisplatin was added to RD cells and processed for $16 \mathrm{~h}$; iii) $0.5 \mathrm{~g} / 1$ Mat group, $0.5 \mathrm{~g} / 1$ Mat was added to RD cells and processed for $24 \mathrm{~h}$; iv) $1.0 \mathrm{~g} / 1$ Mat group, $1.0 \mathrm{~g} / 1$ Mat was added to RD cells and processed for $24 \mathrm{~h}$; v) $1.5 \mathrm{~g} / 1$ Mat group, $1.5 \mathrm{~g} / 1 \mathrm{Mat}$ was added to RD cells and processed for $24 \mathrm{~h}$; vi) $0.5 \mathrm{~g} / 1$ Mat combined with cisplatin group, $0.5 \mathrm{~g} / 1$ Mat was added to RD cells and processed for $24 \mathrm{~h}$, followed by the addition of $5 \mathrm{mg} / \mathrm{l}$ cisplatin and processed for $16 \mathrm{~h}$; vii) $1.0 \mathrm{~g} / \mathrm{l}$ Mat combined with cisplatin group, $1.0 \mathrm{~g} / \mathrm{l}$ Mat was added to RD cells and processed for $24 \mathrm{~h}$, followed by the addition of $5 \mathrm{mg} / \mathrm{l}$ cisplatin and processed for $16 \mathrm{~h}$; and viii) $1.5 \mathrm{~g} / \mathrm{l} \mathrm{Mat}$ combined with cisplatin group, $1.5 \mathrm{~g} / \mathrm{l}$ Mat was added to RD cells and processed for $24 \mathrm{~h}$, followed by the addition of $5 \mathrm{mg} / 1$ cisplatin and processed for $16 \mathrm{~h}$.

MTT detection of RD cell proliferation inhibitory rate. RD cells were collected in the logarithmic phase of growth, and adjusted to a concentration of $1 \times 10^{5} / 1$. The cell suspension $(100 \mu \mathrm{l})$ was then inoculated into appropriate wells of a 96-well plate. Five repeats of each condition were prepared. After the cells were allowed to adhere to the plate for $24 \mathrm{~h}$, they were treated in accordance with the above groupings. After $24 \mathrm{~h}$, the assay was performed as previously described (21). Absorbance of each group was taken at $570 \mathrm{~nm}$ using a microplate reader (Bio-Rad, Hercules, CA, USA), and the cell proliferation inhibition rate of each group was calculated. The experiment was repeated three times.

Flow cytometry mediated detection of RD cell apoptotic rate. RD cells were collected in the logarithmic phase and adjusted to a concentration of $1 \times 10^{5} / 1$. The cells were subsequently inoculated into 6-well plates, with each well containing $2 \mathrm{ml}$ RPMI-1640 medium. After the cells were allowed to adhere to the plate, they were treated in accordance with the above groupings. After $24 \mathrm{~h}$, the apoptotic rate of each group was assessed using an Annexin V-FITC kit according to the manufacturer's instructions. The experiment was repeated three times.

RT-PCR detection of XIAP $m R N A$. Total RNA extraction was then carried out. Briefly, harvested cells in suspension were adjusted to a concentration of $1 \times 10^{6} / 1$, and inoculated into cell culture flasks. The cells were then treated in accordance with the above groupings. After $24 \mathrm{~h}$, the cells were collected again and total RNA was extracted. Subsequently, $5 \mu 1$ of RNA was added to $2 \%$ agarose gel for electrophoresis for detection of its quality, and the RNA concentration and purity were detected using ultraviolet spectrophotometry using GeneQuant Pro (Amersham Biosciences, Little Chalfont, UK). RT was then performed. For PCR amplification, XIAP primer sequences and internal reference sequences (GAPDH) were identified (Table I). Amplification conditions used were: Pre-degenerated under $94^{\circ} \mathrm{C}$ for $2 \mathrm{~min}$, degenerated under $94^{\circ} \mathrm{C}$ for $30 \mathrm{sec}$, annealed under $55^{\circ} \mathrm{C}$ for $45 \mathrm{sec}$, extended under $72^{\circ} \mathrm{C}$ for $30 \mathrm{sec}$, for a total 32 cycles, and then extended under $72^{\circ} \mathrm{C}$ for $10 \mathrm{~min}$. This was followed by agarose gel electrophoresis on the amplification products. The ImageJ software (National Institutes of Health, Bethesda, Maryland, USA) was used to analyze the gray level of the bands after electrophoresis, and the gene expression levels were calculated by the ratio of target gene to the level of the internal amplification product. The experiment was repeated three times.

Statistical analysis. SPSS 16.0 statistical software (Chicago, IL, USA) was used for statistical analysis. Data were presented as mean \pm standard deviation (SD). A normality and homogeneity test of variance was performed on the experimental data and variance analysis of two-factor factorial design was applied to make comparisons among groups. The Student-Newman-Keuls q-test was used in performing pairwise comparison. $\mathrm{P}<0.05$ was considered to be statistically significant.

\section{Results}

Mat and cisplatin act synergistically to inhibit the proliferation of RD cells. Using an MTT assay, it was observed that the proliferation of RD cells in each experimental group was inhibited to different degrees, compared with the control group. As the drug concentration increased, the proliferation inhibition effect was gradually increased $(\mathrm{P}<0.05)$. The proliferation inhibition rate of Mat combined with the cisplatin groups was significantly higher than those of the single Mat and single cisplatin groups under the same concentration $(\mathrm{P}<0.01)$. These data suggested that Mat and cisplatin act synergistically to inhibit the proliferation of RD cells (Table II and Fig. 1).

Mat and cisplatin act cooperatively to induce apoptosis of $R D$ cells. Flow cytometry results showed that, compared with the control group, the apoptotic rate of RD cells in each experimental group was increased to varying degrees $(\mathrm{P}<0.05)$. An increase in drug concentration, led to the apoptotic rate of RD cells in single Mat groups being gradually increased $(\mathrm{P}<0.05)$. The apoptotic rate of Mat combined with the cisplatin groups 
Table I. Primer sequence and annealing temperature of the XIAP and reference genes.

\begin{tabular}{llcc}
\hline Gene & \multicolumn{1}{c}{ Primer $\left(5^{\prime} \rightarrow 3^{\prime}\right)$} & $\begin{array}{c}\text { PCR amplification } \\
\text { products size }(\mathrm{bp})\end{array}$ & $\begin{array}{c}\text { Annealing } \\
\text { temperature }\left({ }^{\circ} \mathrm{C}\right)\end{array}$ \\
\hline$X I A P$ & Sense: & ATGGGATTTGATTTCAAGGA & 256 \\
& Antisense: & GTCCACAAGGAATAAAAACA & \\
GAPDH & Sense: & ACCACAGTCCATGCCATCAC & 452 \\
& Antisense: & TCCACCACCCTGTTGCTGTA & 55 \\
& & & \\
\hline
\end{tabular}

XIAP, X-linked inhibitor of apoptosis protein.

Table II. Proliferation inhibition rate, apoptosis rate and XIAP mRNA expression level ( $\mathrm{n}=3$, mean \pm SD) of each group.

\begin{tabular}{|c|c|c|c|}
\hline Group & Proliferation inhibition rate $(\%)$ & Apoptosis rate $(\%)$ & XIAP expression (FI) \\
\hline Control & $7.60 \pm 6.22$ & $7.80 \pm 0.85$ & $0.90 \pm 0.57$ \\
\hline Cisplatin & $29.83 \pm 1.60^{\mathrm{a}}$ & $22.33 \pm 0.97^{\mathrm{a}}$ & $0.36 \pm 0.04^{\mathrm{a}}$ \\
\hline \multicolumn{4}{|l|}{ Mat } \\
\hline $0.5 \mathrm{~g} / 1$ & $15.93 \pm 2.50^{\mathrm{a}}$ & $12.63 \pm 0.85^{\mathrm{a}}$ & $0.67 \pm 0.06^{\mathrm{a}}$ \\
\hline $1.0 \mathrm{~g} / 1$ & $23.20 \pm 2.33^{\mathrm{a}, \mathrm{b}}$ & $16.93 \pm 0.81^{\mathrm{a}, \mathrm{b}}$ & $0.50 \pm 0.03^{\mathrm{a}, \mathrm{b}}$ \\
\hline $1.5 \mathrm{~g} / 1$ & $36.73 \pm 2.48^{\mathrm{a}, \mathrm{b}}$ & $27.63 \pm 0.70^{\mathrm{a}, \mathrm{b}}$ & $0.28 \pm 0.04^{\mathrm{a}, \mathrm{b}}$ \\
\hline \multicolumn{4}{|c|}{ Mat + cisplatin } \\
\hline $0.5 \mathrm{~g} / 1$ & $46.00 \pm 1.45^{\mathrm{a}, \mathrm{c}}$ & $36.47 \pm 3.00^{\mathrm{a}, \mathrm{c}}$ & $0.21 \pm 0.02^{\mathrm{a}, \mathrm{c}}$ \\
\hline $1.0 \mathrm{~g} / 1$ & $56.27 \pm 2.24^{\mathrm{a}, \mathrm{c}, \mathrm{d}}$ & $44.03 \pm 2.06^{\mathrm{a}, \mathrm{c}, \mathrm{d}}$ & $0.14 \pm 0.02^{\mathrm{a}, \mathrm{c}, \mathrm{d}}$ \\
\hline $1.5 \mathrm{~g} / 1$ & $68.83 \pm 1.35^{\mathrm{a}, \mathrm{c}, \mathrm{d}}$ & $69.00 \pm 5.48^{\mathrm{a}, \mathrm{c}, \mathrm{d}}$ & $0.07 \pm 0.03^{\mathrm{a}, \mathrm{c}, \mathrm{d}}$ \\
\hline F-value & 141.581 & 203.905 & 162.600 \\
\hline P-value & 0.01 & $<0.0001$ & $<0.0001$ \\
\hline
\end{tabular}

${ }^{\mathrm{a} C}$ Comparison with the control group; ${ }^{\mathrm{b}}$ comparison with the $0.5 \mathrm{~g} / \mathrm{l}$ Mat group; ${ }^{\mathrm{c}}$ comparison with $0.5 \mathrm{~g} / \mathrm{l}$ Mat combined with the cisplatin group; $\mathrm{P}<0.05$. ${ }^{\mathrm{d} C o m p a r i s o n}$ between the Mat group and Mat combined with cisplatin at different concentrations were statically significant $(\mathrm{P}<0.05)$. Mat, matrine; XIAP, X-linked inhibitor of apoptosis protein.

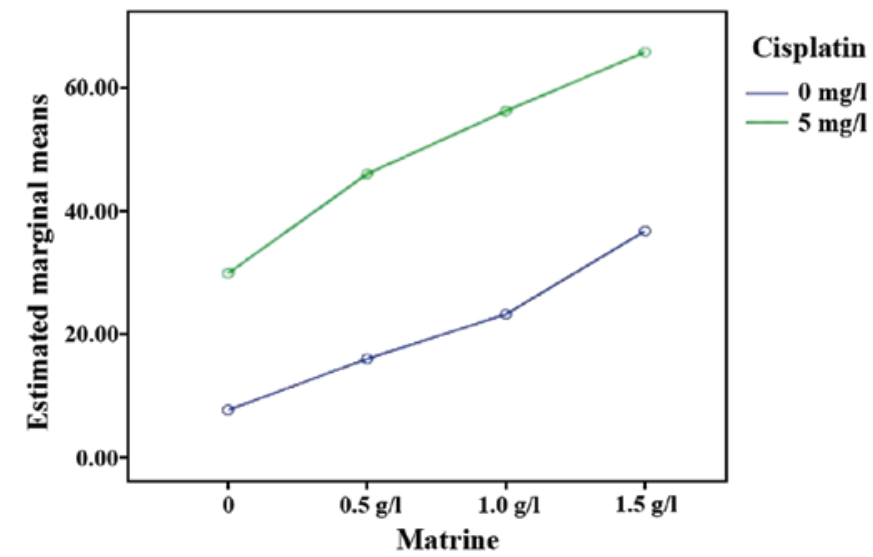

Figure 1. Interaction effect sketch map (proliferation inhibition rate of $\mathrm{RD}$ cells). The green line is the inhibitory rate of cell proliferation in the Mat group combined with cisplatin at different concentrations. The blue line is the inhibitory rate of cell proliferation in the Mat monotherapy group at different concentrations. Mat, matrine.

was significantly higher than those of the single cisplatin and single Mat groups under the same concentration $(\mathrm{P}<0.05)$. Consistent with the observation on the inhibition of cell proliferation, Mat and cisplatin acted cooperatively to induce the apoptosis of RD cells (Table II; Figs. 2 and 3).

Mat and cisplatin act synergistically to reduce the XIAP $m R N A$ expression levels. XIAP mRNA was expressed in cells of the control and each experimental group. The expression levels of XIAP mRNA in RD cells of each experimental group were lower than those in the control group $(\mathrm{P}<0.05)$. Compared with the single cisplatin group, the expression levels of XIAP mRNA in Mat combined with the cisplatin group were significantly reduced $(\mathrm{P}<0.05)$. Compared with the single Mat groups under the same concentration, the expression levels of XIAP mRNA in the Mat combined with cisplatin group were significantly reduced $(\mathrm{P}<0.01)$. These data showed that Mat and cisplatin act synergistically to reduce the expression levels of XIAP mRNA (Table II; Figs. 4 and 5).

\section{Discussion}

RMS is the most common soft tissue sarcoma in children, accounting for $4-8 \%$ of all malignant pediatric solid tumors (22), and 53\% of soft tissue sarcomas (23). RMS can appear in any part of the body. It is most commonly seen in 

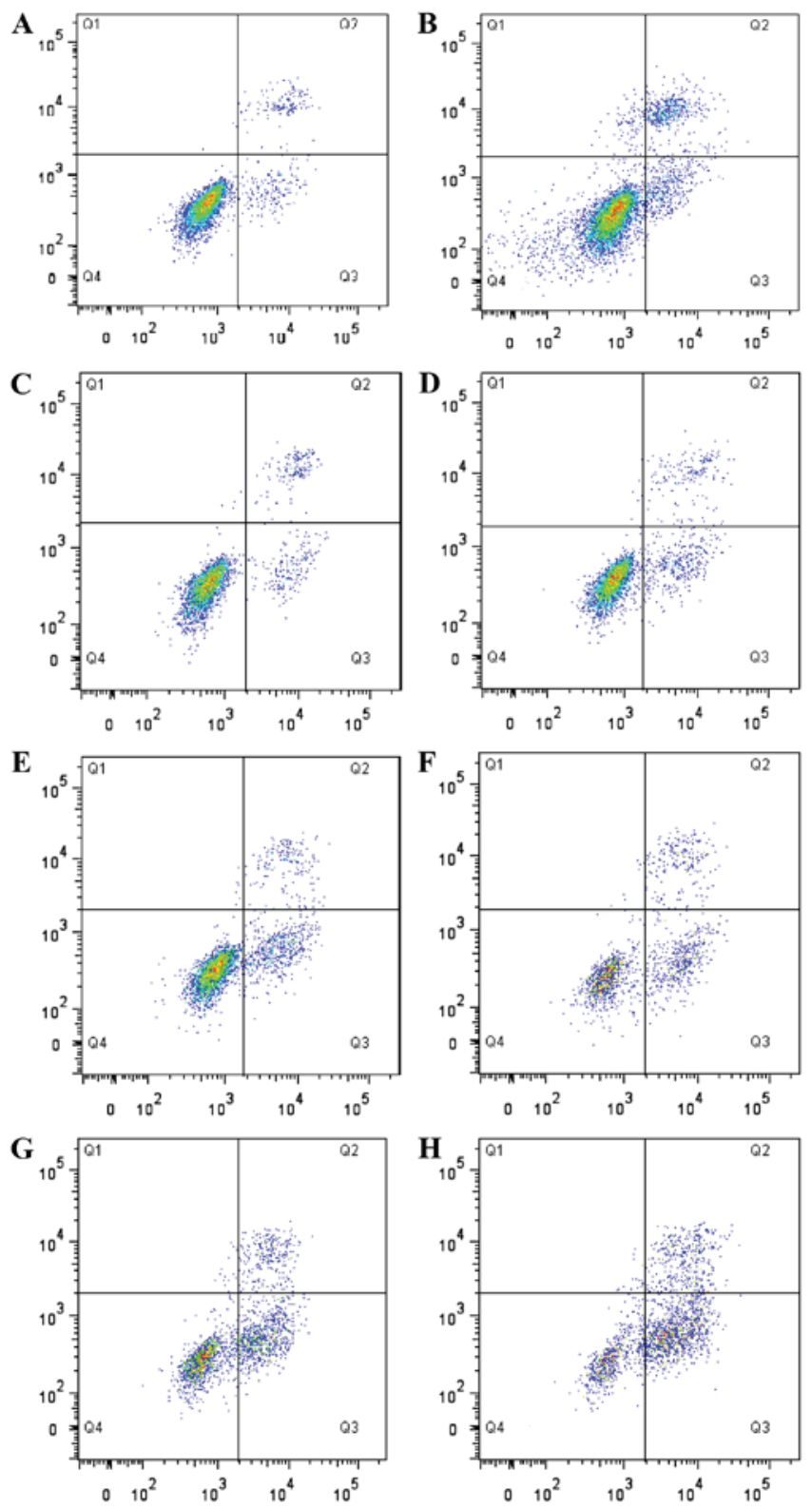

Figure 2. Flow cytometry mediated detection of apoptosis of RD cells. (A) Positive control group, (B) $5 \mathrm{mg} / 1$ cisplatin group, (C) $0.5 \mathrm{~g} / \mathrm{l} \mathrm{Mat}$ group, (D) $1.0 \mathrm{~g} / 1$ Mat group, (E) $1.5 \mathrm{~g} / 1$ Mat group, (F) $0.5 \mathrm{~g} / 1$ matrine combined with cisplatin group, (G) $1.0 \mathrm{~g} / 1$ Mat combined with cisplatin group, $(\mathrm{H}) 1.5 \mathrm{~g} / 1$ Mat combined with $5 \mathrm{mg} / \mathrm{l}$ cisplatin group. The upper left quadrant $(\mathrm{Q} 1)$ shows cells under mechanical injury (Annexin $\mathrm{V}^{-} / \mathrm{PI}^{+}$); upper right quadrant (Q2) shows cells under advanced apoptosis and secondary necrosis (Annexin $\mathrm{V}^{+} / \mathrm{PI}^{+}$); lower left quadrant (Q4) shows surviving cells (Annexin $\mathrm{V}^{-} / \mathrm{PI}$ ); lower right quadrant shows cells undergoing early apoptosis $\left(\right.$ Annexin $\left.\mathrm{V}^{+} / \mathrm{PI}\right)$. Mat, matrine.

the head and neck of children and is characterized by high malignancy and rapid progression (24). It is challenging to diagnose the disease in its early stages. When patients arrive under hospital care, the disease is at an advanced stage and the tumor cannot be removed by surgery. At this point, comprehensive therapy by combining surgery with chemo- and radiotherapy should be utilized. Drug resistance to chemotherapy often results in treatment failure. Therefore, the need to improve the curative effect of chemotherapy drugs, and reverse the drug resistance of tumor cells has become a research hotspot.

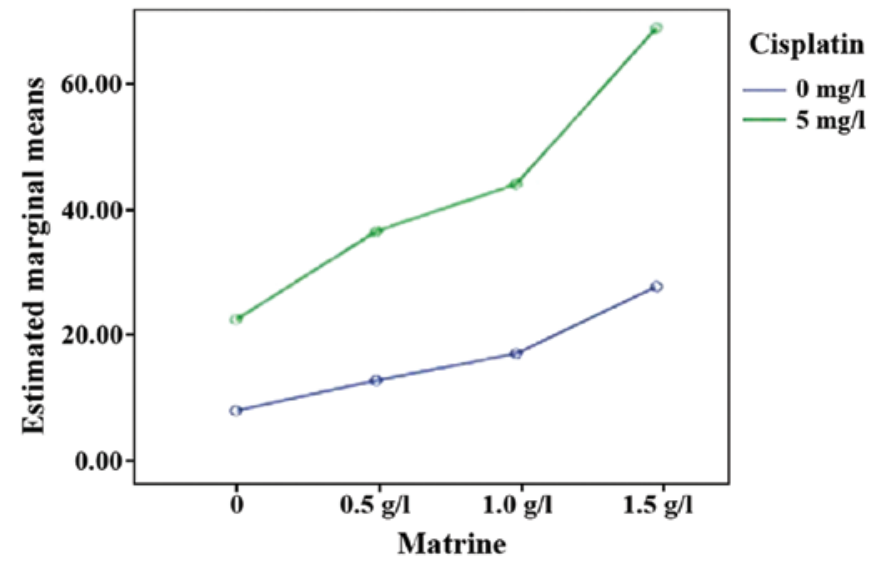

Figure 3. Interaction effect sketch map (apoptosis rate of RD cells). The green line is the cell apoptosis rate in the Mat group combined with cisplatin at different concentrations. The blue line is the cell apoptotic rate in the Mat monotherapy group at different concentrations. Mat, matrine.

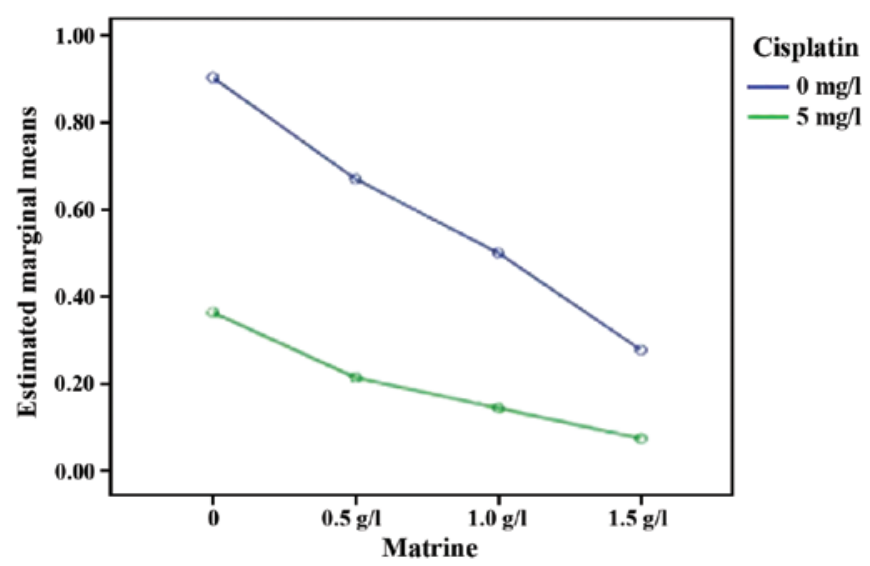

Figure 4. Interaction effect sketch map (the expression level of XIAP in $\mathrm{RD}$ cells). The green line is the expression level of XIAP in the Mat group combined with cisplatin at different concentrations. The blue line is the expression level of XIAP in the Mat monotherapy group at different concentrations. Mat, matrine; XIAP, X-linked inhibitor of apoptosis protein.

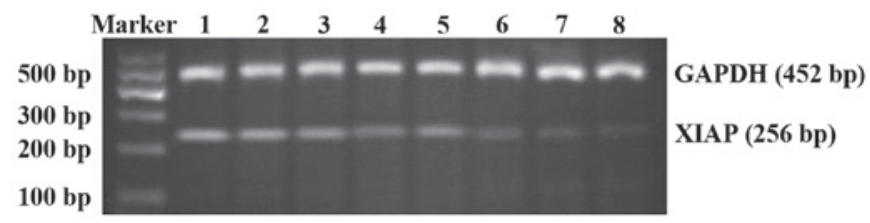

Figure 5. XIAP mRNA expression in each group of RD cells. The upper band is the internal reference (GAPDH). The lower band is the target band (XIAP). Lane 1, control group; lane 2, $0.5 \mathrm{~g} / 1$ Mat group; lane 3, $1.0 \mathrm{~g} / 1$ Mat group; lane 4, $1.5 \mathrm{~g} / 1$ Mat group; lane 5, mg/l cisplatin group; lane 6, $0.5 \mathrm{~g} / \mathrm{l} \mathrm{Mat}$ combined with cisplatin group; lane 7,1.0 g/l Mat combined with cisplatin group; and lane 8, $1.5 \mathrm{~g} / \mathrm{l}$ Mat combined with cisplatin group. XIAP, X-linked inhibitor of apoptosis protein; Mat, matrine.

In recent years, the traditional Chinese medicine, Mat, has increasingly aroused the interest of scholars due to its physicochemical properties of low toxicity and high efficacy. Previous findings have shown that Mat had a significant inhibitory effect on a variety of tumor cells, such as neuroblastoma, medulloblastoma, colorectal cancer, nasopharyngeal carcinoma, leukemia cells and RMS (25-31). In 
addition, the antitumor mechanism of Mat mainly included obstructing tumor cell cycle progression, inhibiting tumor cell proliferation, inducing tumor cell apoptosis and reversing chemotherapy drug resistance (32).

Guo et al (33) and Li et al (34) investigated the 24 and $48 \mathrm{~h}$ effects of different concentrations of Mat on RMS. The results have confirmed that Mat inhibited the proliferation of RMS, inducing cell apoptosis and maintaining the cell cycle in the G0/G1 phase. The results of the present study have shown that the proliferation inhibition rate and apoptosis rate of RD cells treated at different concentrations of Mat $(0.5,1.0$ and $1.5 \mathrm{~g} / \mathrm{l})$ were higher than those in the control group. Additionally, as the concentration of Mat increased, the apoptosis rate of RD cells also increased, confirming that Mat suppressed the proliferation and induced the apoptosis of RMS cells. The effect was dose-dependent to a certain degree. Our experimental results were consistent with those of Guo et al and Li et al $(33,34)$.

Thanks to its broad anticancer properties, cisplatin has occupied an extremely significant and unique position in the field of cancer treatment since 1970 (35). It is commonly regarded as an anticancer drug with epoch-making significance, particularly effective for urogenital tumors and malignant carcinomas of the neck (35). However, as the use of cisplatin became increasingly widespread, it became apparent that it had toxic side effects while killing cancer cells and that most of these side effects were related to the dose of cisplatin. The toxic side effects of cisplatin mainly manifested as a result of its application in the clinic. However, approaches regarding how to reduce the toxicity and side effects of cisplatin have become an area of interest in clinical research. Further studies on cisplatin revealed that it had synergistic effects with multiple other drugs. Drug combinations can enhance their antitumor effects, reduce the required dose of cisplatin, and reduce the toxic side effect of cisplatin. Sárosi and Lénárt showed that the combination of gemcitabine and cisplatin was effective in the treatment of advanced non-small cell lung cancer, and that the side effects were relatively minor (36). Solár et al have shown that geldanamycin enhanced the cytotoxic effect of cisplatin on tumor cells (37).

In recent years, as research on the antitumor effects of Chinese medicine progressed, investigators examined how to enhance the anticancer effect of antitumor drugs while lowering their toxicity and side effects. Several studies have shown that rhubarb, bufalin, Radix Astragali, Shengmai, Mat and other traditional Chinese medicines may enhance the anticancer effects of cisplatin to varying degrees (38-41). However, to the best of our knowledge, few studies focused on the effects of Mat combined with cisplatin on RMS. In the present study, we used Mat at different concentration (final concentrations were $0.5,1.0$ and $1.5 \mathrm{~g} / \mathrm{l}$ ) in combination with cisplatin (final concentration was $5 \mathrm{mg} / \mathrm{l}$ ) to treat RMS RD cells cultured in vitro. We then used the MTT assay, flow cytometry and RT-PCR to measure the effects on proliferation inhibition and apoptosis of RD cells. The results of the present study show that the proliferation inhibition rate and apoptosis rate of RD cells in Mat (different concentrations) combined with cisplatin groups was significantly higher than that in the single Mat or cisplatin groups. Our study also confirmed that Mat and cisplatin produced a synergistic effect, and that the combination therapy can significantly kill RMS RD cells.
In recent years, with the extensive clinical application of cisplatin, the phenomenon of cisplatin resistance has become increasingly widespread, which has generated interest among scholars to explore the mechanisms of drug resistance. Amantana et al have shown that DU145 prostate cancer cells were resistant to cisplatin and that high expression levels of XIAP were a cause of DU145 resistance to cisplatin. The study also confirmed that antisense nucleic acid therapy of XIAP can enhance the antitumor effect of cisplatin and increase the sensitivity of the DU145 cell line to cisplatin (42). XIAP is a new member of the IAPs family and also one of the most powerful inhibitors of apoptosis $(23,24)$. At present, XIAP has been shown to be a protein of universal expression. It is expressed in various human tissues $(25,26)$, but at low levels in normal tissue cells and is increased in cancer cells (27-29). We have studied the effects of different concentrations of Mat in combination with cisplatin on the expression of XIAP in human RMS RD cells using RT-PCR analysis. The results showed that XIAP was expressed in RMS RD cells. Following treatment with Mat and/or cisplatin, the expression levels of $\mathrm{XIAP}$ in the cells were decreased. In the dose-response experiments, XIAP mRNA decreased as a function of increasing Mat concentration. The expression of XIAP mRNA was significantly reduced under the combined effect of Mat and cisplatin versus Mat or cisplatin alone.

In conclusion, our experimental results show that Mat combined with cisplatin inhibited the expression of XIAP in RMS RD cells and induced apoptosis in these tumor cells. The results also indicate that Mat may lower the tolerance of RMS RD cells to cisplatin by inhibiting the expression of XIAP, thus improving the curative effect of cisplatin. We believe this study reveals a potential new target for the study of drug-resistant RMS cell lines and may also lead to new therapeutic options for the clinical treatment of RMS.

\section{References}

1. Song YQ, Liu SP, Liu ZF and Hu XL: Determination of matrine and oxymatrine in Radix Sophorae Flavescentis by resonance rayleigh scattering, second-order scattering and frequency doubling scattering technique. Chem Res Chin Univ 27: 746-749, 2011.

2. Zhaowu Z, Xiaoli W, Yangde Z and Nianfeng L: Preparation of matrine ethosome, its percutaneous permeation in vitro and anti-inflammatory activity in vivo in rats. J Liposome Res 19: 155-162, 2009.

3. Niu H, Zhang Y, Wu B, Zhang Y, Jiang H and He P: Matrine induces the apoptosis of lung cancer cells through downregulation of inhibitor of apoptosis proteins and the Akt signaling pathway. Oncol Rep 32: 1087-1093, 2014.

4. Liu YQ, Li Y, Qin J, Wang Q, She YL, Luo YL, He JX, Li JY and Xie XD: Matrine reduces proliferation of human lung cancer cells by inducing apoptosis and changing miRNA expression profiles. Asian Pac J Cancer Prev 15: 2169-2177, 2014.

5. Li H, Li X, Bai M, Suo Y, Zhang G and Cao X: Matrine inhibited proliferation and increased apoptosis in human breast cancer MCF-7 cells via upregulation of Bax and downregulation of Bcl-2. Int J Clin Exp Pathol 8: 14793-14799, 2015.

6. Gao H, Guo Y, Deng N, Fei P, Qiu X, Zheng P, Feng J and Dai G: Suppressive effect of matrine on tumor invasion in N-butyl-N-4-hydroxybutyl)nitrosamine-induced urinary bladder carcinogenesis. Chemotherapy 60: 119-128, 2014.

7. Li Q, Lai Y, Wang C, Xu G, He Z, Shang X, Sun Y, Zhang F, Liu L and Huang H: Matrine inhibits the proliferation, invasion and migration of castration-resistant prostate cancer cells through regulation of the NF- $\kappa \mathrm{B}$ signaling pathway. Oncol Rep 35: 375-381, 2016. 
8. Rong B, Zhao C, Gao W and Yang S: Matrine promotes the efficacy and safety of platinum-based doublet chemotherapy for advanced non-small cell lung cancer. Int J Clin Exp Med 8: 14701-14717, 2015.

9. Wang HQ, Jin JJ and Wang J: Matrine induces mitochondrial apoptosis in cisplatin-resistant non-small cell lung cancer cells via suppression of $\beta$-catenin/survivin signaling. Oncol Rep 33: 2561-2566, 2015.

10. Flanagan L, Sebastià J, Tuffy LP, Spring A, Lichawska A, Devocelle M, Prehn JH and Rehm M: XIAP impairs Smac release from the mitochondria during apoptosis. Cell Death Dis 1: e49, 2010.

11. Kempkensteffen C, Jäger T, Bub J, Weikert S, Hinz S, Christoph F, Krause H, Schostak M, Miller K and Schrader M: The equilibrium of XIAP and Smac/DIABLO expression is gradually deranged during the development and progression of testicular germ cell tumours. Int J Androl 30: 476-483, 2007.

12. Ramp U, Krieg T, Caliskan E, Mahotka C, Ebert T, Willers R, Gabbert HE and Gerharz CD: XIAP expression is an independent prognostic marker in clear-cell renal carcinomas. Hum Pathol 35: 1022-1028, 2004.

13. Hanson AJ, Wallace HA, Freeman TJ, Beauchamp RD, Lee LA and Lee E: XIAP monoubiquitylates Groucho/TLE to promote canonical Wnt signaling. Mol Cell 45: 619-628, 2012.

14. Zheng ZL, Tan LZ, Yu YP, Michalopoulos G and Luo JH: Interaction of CSR1 with XIAP reverses inhibition of caspases and accelerates cell death. Am J Pathol 181: 463-471, 2012.

15. Berezovskaya O, Schimmer AD, Glinskii AB, Pinilla C, Hoffman RM, Reed JC and Glinsky GV: Increased expression of apoptosis inhibitor protein XIAP contributes to anoikis resistance of circulating human prostate cancer metastasis precursor cells. Cancer Res 65: 2378-2386, 2005.

16. Doudican NA, Byron SA, Pollock PM and Orlow SJ: XIAP downregulation accompanies mebendazole growth inhibition in melanoma xenografts. Anticancer Drugs 24: 181-188, 2013.

17. Castells M, Milhas D, Gandy C, Thibault B, Rafii A, Delord JP and Couderc B: Microenvironment mesenchymal cells protect ovarian cancer cell lines from apoptosis by inhibiting XIAP inactivation. Cell Death Dis 4: e887, 2013.

18. Cao Z, Li X, Li J, Luo W, Huang C and Chen J: X-linked inhibitor of apoptosis protein (XIAP) lacking RING domain localizes to the nuclear and promotes cancer cell anchorage-independent growth by targeting the E2F1/Cyclin E axis. Oncotarget 5: 7126-7137, 2014.

19. Liew JC1, Tan WS, Alitheen NB, Chan ES and Tey BT: Over-expression of the X-linked inhibitor of apoptosis protein (XIAP) delays serum deprivation-induced apoptosis in CHO-K1 cells. J Biosci Bioeng 110: 338-344, 2010.

20. Katragadda L, Carter BZ and Borthakur G: XIAP antisense therapy with AEG 35156 in acute myeloid leukemia. Expert Opin Investig Drugs 22: 663-670, 2013.

21. Yang CL, Liu SS, Ma YG, Liu YY, Xue YX and Huang B: The influence of intraoperative pleural perfusion with matrinecisplatin or cisplatin on stromal cell-derived factor-1 in non-small cell lung cancer patients with subclinical pleural metastasis. Med Oncol 29: 574-581, 2012.

22. Rossi S, Stoppani E, Puri PL and Fanzani A: Differentiation of human rhabdomyosarcoma RD cells is regulated by reciprocal, functional interactions between myostatin, p38 and extracellular regulated kinase signalling pathways. Eur J Cancer 47: 1095-1105, 2011.

23. Paulino AC and Okcu MF: Rhabdomyosarcoma. Curr Probl Cancer 32: 7-34, 2008.

24. Panta P and Felix D: Rhabdomyosarcoma: a rapidly growing malignancy. Pan Afr Med J 22: 121, 2015.

25. Li H, Xie S, Liu X, Wu H, Lin X, Gu J, Wang H and Duan Y: Matrine alters microRNA expression profiles in SGC-7901 human gastric cancer cells. Oncol Rep 32: 2118-2126, 2014.
26. Meng F, Zhang ZX, Xie J, Huang CB, Liu Y and Liao YG: Effects of matrine on the apoptosis and the expression of PEG10 in human hepatocarcinoma cell Line HepG2. J Pract Med 10: 1523-1526, 2014 (In Chinese).

27. Gao XH, Xu W, Li WJ, Ma HW and Bai YL: Anti-proliferative effects of matrine on human neuroblastoma SK-N-SH cells Chin J Exp Trad Med Formulae 23: 196-199, 2013 (In Chinese).

28. Yu Q1, Chen B, Zhang X, Qian W, Ye B and Zhou Y: Arsenic trioxide-enhanced, matrine-induced apoptosis in multiple myeloma cell lines. Planta Med 79: 775-781, 2013.

29. Yan F, Liu Y and Wang W: Matrine inhibited the growth of rat osteosarcoma UMR-108 cells by inducing apoptosis in a mitochondrial-caspase-dependent pathway. Tumour Biol 34: 2135-2140, 2013.

30. Guo L, Xue TY, Xu W and Gao JZ: Matrine promotes G0/G1 arrest and down-regulates cyclin D1 expression in human rhabdomyosarcoma cells. Panminerva Med 55: 291-296, 2013.

31. Tan C, Qian X, Jia R, Wu M and Liang Z: Matrine induction of reactive oxygen species activates $\mathrm{p} 38$ leading to caspase-dependent cell apoptosis in non-small cell lung cancer cells. Oncol Rep 30: 2529-2535, 2013.

32. Liu Y, Xu Y, Ji W, Li X, Sun B, Gao Q and Su C: Anti-tumor activities of matrine and oxymatrine: literature review. Tumour Biol 35: 5111-5119, 2014.

33. Guo L, Xue TY, Xu W and Gao JZ: Effects of matrine on the proliferation and apoptosis of human rhabdomyosarcoma RD cells. Zhongguo Dang Dai Er Ke Za Zhi 14: 780-784, 2012 (In Chinese).

34. Li YX: Effects and mechanisms of matrine on proliferation and apoptosis of human rhabdomyosarcoma cell RD. Seek Med Ask Med: 10: 295-296, 2012.

35. Miao L, Guo S, Zhang J, Kim WY and Huang L: Nanoparticles with precise ratiometric co-loading and co-delivery of gemcitabine monophosphate and cisplatin for treatment of bladder cancer. Adv Funct Mater 24: 6601-6611, 2014.

36. Sárosi V and Lénárt T: Gemcitabine-cisplatin combination in the first line treatment of non-small cell lung cancer. Our experience and analysis of safety. Magy Onkol 47: 189-193, 2003 (In Hungarian).

37. Solár P, Horváth V, Kleban J, Koval' J, Solárová Z, Kozubík A and Fedorocko P: Hsp90 inhibitor geldanamycin increases the sensitivity of resistant ovarian adenocarcinoma cell line A2780cis to cisplatin. Neoplasma 54: 127-130, 2007.

38. Huang Q, Lu G, Shen HM, Chung MC and Ong CN: Anti-cancer properties of anthraquinones from rhubarb. Med Res Rev 27: 609-630, 2007.

39. Yin PH, Liu X, Qiu YY, Cai JF, Qin JM, Zhu HR and Li Q: Anti-tumor activity and apoptosis-regulation mechanisms of bufalin in various cancers: new hope for cancer patients. Asian Pac J Cancer Prev 13: 5339-5343, 2012.

40. Tang MX: Reduction of metastasis of lung cancer by 'Fufang Shengmai-compound pulse inducer' - a preliminary report on experimental, clinical and pathologic study with reference to the ultrastructure. Zhonghua Zhong Liu Za Zhi 5: 176-179, 1983 (In Chinese).

41. Xiao WL, Motley TJ, Unachukwu UJ, Lau CB, Jiang B, Hong F, Leung PC, Wang QF, Livingston PO, Cassileth BR, et al: Chemical and genetic assessment of variability in commercial Radix Astragali (Astragalus spp.) by ion trap LC-MS and nuclear ribosomal DNA barcoding sequence analyses. J Agric Food Chem 59: 1548-1556, 2011.

42. Amantana A, London CA, Iversen PL and Devi GR: X-linked inhibitor of apoptosis protein inhibition induces apoptosis and enhances chemotherapy sensitivity in human prostate cancer cells. Mol Cancer Ther 3: 699-707, 2004. 